\title{
Efficiency of zero emission cycles on the basis of their configuration
}

\author{
Pavel Shchinnikov ${ }^{1}$, Olesya Borush ${ }^{1}$, Alina Frantseva ${ }^{1}$, and Ivan Sadkin ${ }^{1, *}$ \\ ${ }^{1}$ Novosibirsk State Technical University, Novosibirsk, Russia
}

\begin{abstract}
In this work, a study of the efficiency of carbon dioxide energy cycles of different architecture is carried out. The relevance of these technical solutions in modern conditions is shown. Basic options of zero emission thermodynamic cycles using $\mathrm{CO}_{2}$ as an cycle fluid are presented. It is shown that the efficiency of the analyzed $\mathrm{CO}_{2}$-cycles with an initial temperature of $1000{ }^{\circ} \mathrm{C}$ will be $54-58 \%$, depending on their configuration. It is presented that the efficiency can be increased up to $65 \%$ with an initial temperature increase up to $1500{ }^{\circ} \mathrm{C}$.
\end{abstract}

\section{Introduction}

The Concept of Sustainable Development provides reduction of anthropogenic $\mathrm{CO}_{2}$ emissions by 2.1 times by 2040 compared to 2018 and has a goal to achieve carbon neutrality after 2050. [1]. At the same time many European countries and USA are actively developing mechanisms of economic regulation and taxes on emissions [2,3]. So it is really possible that products and energy with high carbon footprint may turn out to be uncompetitive. On the other hand, the share of fossil fuels in the global power balance will continue to be the largest (at a level of 58\%), while coal consumption remains at 1.47 Gtoe. [1]. One of the promising trends in the development of coal-fired power industry is its integrated gasification [4], examples of which are developments in the USA and Japan [5].

To reduce the carbon footprint, technical solutions are being developed to decrease or totally eliminate $\mathrm{CO}_{2}$ emissions into the environment. The utilization of $\mathrm{CO}_{2}$ is assumed by means of liquefaction process and disposal. Such solutions are called "zero emission technologies" in the literature.

One solution is the carbon dioxide energy cycles $[6,7,8,9]$, in which the cycle fluid used is supercritical carbon dioxide. Today, three such solutions are known, which have received the names "Allam cycle" [6,9], "JIHT cycle" [7] and "Graz cycle" [8]. The Allam cycle and the JIHT cycle use carbon dioxide as a cycle fluid, and the Graz cycle uses a mixture of carbon dioxide and water vapor. However, the Graz cycle is actually a twostage cycle, which significantly complicates its implementation. Therefore, the authors do not consider it at the present stage of research.
In the cycles of Allam and JIHT gas is used as fuel, and oxygen is used as an oxydizing agent, which makes the combustion products only $\mathrm{CO}_{2}$ and water vapor due to the hydrogen of the fuel. The use of recirculation of carbon dioxide in order to limit the temperature at the inlet to the gas turbine determines the fact that the working fluid of the cycle is $90-95 \%$ carbon dioxide. In the combustion chamber, the temperature of the cycle fluid rises to the required values due to the combustion of fuel with oxygen. The expansion of the cycle fluid in the turbine occurs up to a pressure of 20-30 bar, which is less than the critical pressure for carbon dioxide. At the outlet of the turbine, the flow of the cycle fluid is directed to the regenerator.

Water is condensed in the regenerator after the expansion of the cycle fluid in the turbine, and pure carbon dioxide remains, suitable for use in technological process or disposing. Thus we have a power plant where $\mathrm{CO}_{2}$ is the only waste-product: no nitrogen and sulfur oxides, bottom ash, etc.

This is one of the advantages of these energy cycles compared to other emission reduction technologies of greenhouse gas emissions from power plants. For example, compared to technologies of separation and capture of carbon dioxide from combustion products (CCS - Carbon Capture and Storage [10,11,12]) of traditional thermal power plants, when it is required to first separate $\mathrm{CO}_{2}$ from the entire gas stream, and only then work with it.

Another important advantage of carbon dioxide energy cycles over CCS technologies is that the creation of a separate compressor facility is not required to compress carbon dioxide, since it is provided for the operation of the cycle itself. Removal of $\mathrm{CO}_{2}$ can be carried out after the pressure boosting system with its

\footnotetext{
${ }^{*}$ Corresponding author: sadkinvanya@mail.ru
} 
operating value, as a result of which a pipeline quality $\mathrm{CO}_{2}$ in a supercritical state can be obtained, suitable for transportation over long distances and disposal at great depths. This is a significant difference from the CCS technology, where $\mathrm{CO}_{2}$ separated from other gases needs to be compressed in some independent installation, which imposes additional costs on its own needs and reduces the final efficiency of energy production.

This article explores four basic options of zero emission carbon dioxide energy cycle. All considered options are adapted to a comparable form in terms of thermodynamic parameters. Further, the article proposes a study of the efficiency of such cycles in order to identify their thermodynamically effective configuration, as well as the composition of equipment for practical implementation.

\section{Modeling}

Modeling is based on rigorous concepts of thermodynamic processes that are realized in each of the considered cycles. Thermodynamic cycles and schematic diagrams for the implementation of zero emissions electrical power generation are shown in Fig. 1. In all cases, $\mathrm{CO}_{2}$ is used as an cycle fluid.

a)

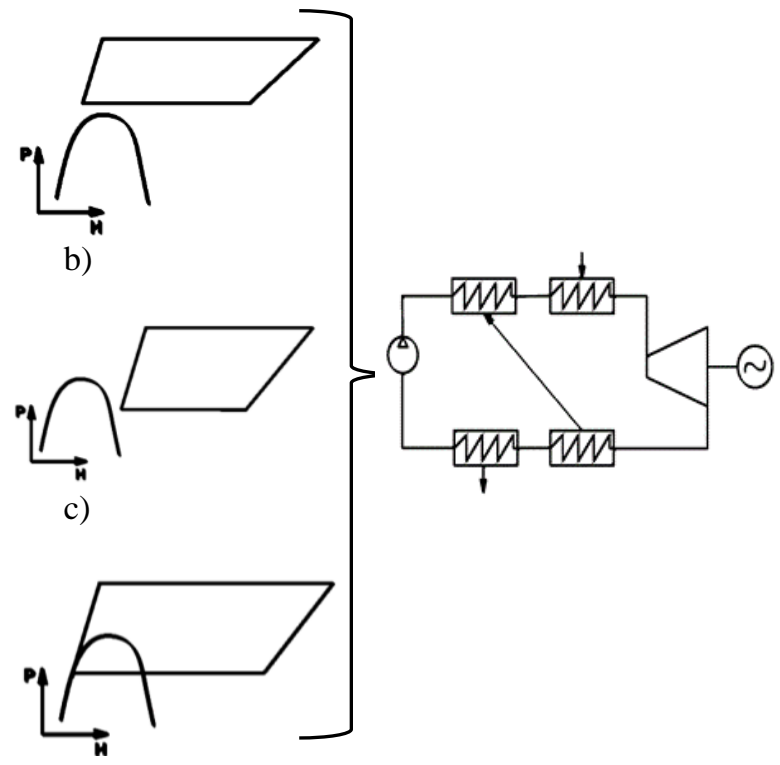

d)
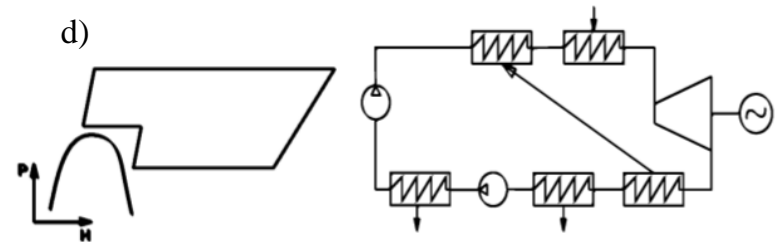

Fig. 1. Thermodynamic cycles and schematic diagrams for the implementation of zero emissions electrical power generation

It can be seen that in all cases the heat supply is provided in the zone of supercritical parameters. In one of the cases under consideration (Fig. $1 \mathrm{c}$ ), a condensation zone is used to remove heat, which simultaneously provides a high heat drop on the turbine and a one-stage pressure increase process using a pump. Otherwise, to maintain a high heat drop on the turbine, it is necessary to have a compressor comparable to it (Fig. $1 \mathrm{~b}$ ) or to provide a two-stage pressure boosting (Fig. $1 \mathrm{~d}$ ). Heat recovery is provided for all cases.

The authors additionally proposed a cycle entirely located in the supercritical zone (Fig. 1a). This configuration of the cycle eliminates the condensation of the working fluid (carbon dioxide) and, at the same time, retains the possibility of using the pump. This is possible due to the properties of supercritical carbon dioxide, the density of which approaches the density of the liquid when its temperature decreases (even to the ambient temperature).

In addition, it can be noted that the scheme with $\mathrm{CO}_{2}$ condensation was first developed by JIHT [7] (Joint Institute for High Temperatures RAS), Fig. 1c, and the scheme of a two-stage pressure boosting - by the Global Energy prize winner R.J Allam [6,9], Fig. 1d. The remaining options of the cycles are proposed for consideration by the authors of the article.

\section{Calculation method}

In the calculations, it is assumed that there are no heat losses from the combustion chamber to the environment, and all the heat released during combustion goes to heating the fuel combustion products $\left(\mathrm{CO}_{2}\right.$ and water vapor) and the main flow of circulating carbon dioxide. The heat of the fuel and oxidizer, which are introduced into the combustion chamber, is not taken into account. All processes are considered as ideal. After the expansion process in the turbine the mixture temperature of $\mathrm{CO}_{2}$ and water vapor is determined according to the $\mathrm{CO}_{2}$ property diagrams, since its mass fraction in the composition of the cycle fluid is more than $95 \%$.

All calculations are made for $1 \mathrm{~kg}$ of carbon dioxide ( $G^{C O_{2}}=1 \mathrm{~kg} / \mathrm{s}$ ) passing through the turbine.

To determine the parameters of the cycle fluid at all key points of the cycle, a system of equations for the material and thermal balance of the combustion chamber and the heat-regenerator is used, taking into account that part of carbon dioxide is continuously generated due to fuel combustion (this part of $\mathrm{CO}_{2}$ is then removed from the cycle), and part is circulating in a cycle. The combustion chamber is essentially a mixing heater, where two gas streams are mixed, so the material balance equation is:

$$
G_{\text {circ. }}^{\mathrm{CO}_{2}}+\delta+G_{\text {comb.prod. }}^{\mathrm{H}_{2} \mathrm{O}}=G^{\mathrm{CO}_{2}}+G_{\text {comb.prod }}^{\mathrm{H}_{2} \mathrm{O}}
$$

where $\delta$ is the amount of carbon dioxide that is introduced into the cycle as a result of oxy-fuel combustion in the combustion chamber, $G_{\text {circ. }}^{\mathrm{CO}_{2}}=(1-\delta)$ is the circulating flow of carbon dioxide.

The energy balance equation for the combustion chamber has the following form:

$$
(1-\delta) \cdot h_{\text {circ. }}^{\mathrm{CO}_{2}}+Q=G^{\mathrm{CO}_{2}} \cdot h_{0}^{\mathrm{CO}_{2}}+G_{\text {steam }}^{\mathrm{H}_{2} \mathrm{O}} \cdot h_{0}^{\mathrm{H}_{2} \mathrm{O}}
$$

Heat-transfer equations between the flows of hot and cold fluid in the regenerative heat exchanger are derived in a similar way. 
Thermal efficiency of cycle is defined as the ratio of the available heat drop minus the work of compression to the supplied heat:

$$
\eta=\frac{H_{0}-l_{c o m p}}{Q}
$$

The available heat drop of the cycle fluid is defined as the sum of the heat drops of carbon dioxide and water vapor:

$$
\mathrm{H}_{0}=\mathrm{H}_{0}^{\mathrm{CO}_{2}}+\mathrm{H}_{0}^{\mathrm{H}_{2} \mathrm{O}}
$$

The available heat drop for carbon dioxide is found as the difference between the enthalpies of $\mathrm{CO}_{2}$ during isentropic expansion from the initial parameters of the working fluid to a given final pressure. Then, the theoretical $\mathrm{CO}_{2}$ temperature after the expansion process is found from the state diagram.

Since the mass fraction of carbon dioxide in the composition of the cycle fluid is about $95 \%$, it is assumed that the final pressure and temperature of the cycle fluid (and water vapor) coincide with the values for carbon dioxide.

The heat drop for water vapor is defined as the difference between the enthalpies of the vapor at the initial parameters of the cycle fluid and the final ones (equal to the parameters of $\mathrm{CO}_{2}$ ). That is, the expansion of the vapor in this case is different from isentropic. Otherwise, it turns out that after the joint expansion of carbon dioxide and water vapor, they will have different final temperatures, which is impossible, since they are a single mixture of the cycle fluid.

In all cases, it is assumed that the entire $\mathrm{CO}_{2}$ flow is first compressed, and then a fraction of carbon dioxide equal to $\delta$ is removed from the cycle under high pressure. Thus, the costs of removing carbon dioxide from the cycle for further use or disposal are considered.

\section{Results and discussions}

Four variants of basic $\mathrm{CO}_{2}$-cycle are accepted for calculations. Heat recovery is provided in all variants. The final pressure is (tentatively) taken at 30 bar by analogy with the Allam cycle [6]. In some variants there is a deviation from this value due to technical necessity.

Description of options:

Option 1 - a supercritical cycle, completely located in the supercritical parameters zone, with a single-stage pressure rise to 300 bar by a pump, Fig. 1a;

Option 2 - supercritical cycle with a single-stage compressor pressure rise to 300 bar, fig. $1 \mathrm{~b}$;

Option 3 - supercritical cycle with carbon dioxide condensation and a single-stage pressure rise to 300 bar by a pump, Fig. 1c (JIHT cycle);

Option 4 - supercritical cycle with a two-stage pressure boosting by a compressor and a pump up to 300 bar, fig. 1d (Allam cycle);

Cooling of the compressible carbon dioxide to ambient temperature before entering the second compression stage is provided in option 4 . This is done to increase the $\mathrm{CO}_{2}$ density and the possibility of using the pump for it boosting.
The initial data for calculations and the obtained values of the thermal efficiency of each option are presented in Table 1. This table shows the efficiency indicators and key characteristics of energy cycles on carbon dioxide of various architectures at an initial temperature of the working fluid of $1000{ }^{\circ} \mathrm{C}$ and initial pressure of 300 bar.

Calculation of efficiency indicators of cycles with other parameters is presented in the form of graphs later in the article.

\begin{tabular}{|c|c|c|c|c|c|}
\hline \multirow{2}{*}{\multicolumn{2}{|c|}{$\begin{array}{l}\text { Parameter name / } \\
\text { physical dimension }\end{array}$}} & \multicolumn{4}{|c|}{ Cycle execution option } \\
\hline & & \multirow{2}{*}{$\frac{1}{1000}$} & \multirow{2}{*}{$\frac{2}{1000}$} & \multirow{2}{*}{$\frac{3}{1000}$} & \multirow{2}{*}{$\begin{array}{c}4 \\
1000\end{array}$} \\
\hline $\begin{array}{l}\text { Initial } \\
\text { temperature }\end{array}$ & ${ }^{\circ} \mathrm{C}$ & & & & \\
\hline $\begin{array}{l}\text { Initial } \\
\text { pressure }\end{array}$ & bar & 300 & 300 & 300 & 300 \\
\hline $\begin{array}{l}\text { Final } \\
\text { pressure }\end{array}$ & bar & 75 & 30 & 57,2 & 30 \\
\hline $\begin{array}{l}\text { Final } \\
\text { temperature }\end{array}$ & ${ }^{\circ} \mathrm{C}$ & 755,6 & 617,7 & 713,2 & 617,7 \\
\hline $\begin{array}{l}\text { Outlet } \\
\text { temperature }\end{array}$ & ${ }^{\circ} \mathrm{C}$ & \multicolumn{4}{|c|}{20 (ambient) } \\
\hline $\begin{array}{l}\mathrm{CO}_{2} \text { temp. } \\
\text { after heat } \\
\text { recovery }\end{array}$ & ${ }^{\circ} \mathrm{C}$ & 713 & 617,7 & 658 & 557,3 \\
\hline $\begin{array}{l}\text { Pressure } \\
\text { after the 1st } \\
\text { stage of } \\
\text { pressure } \\
\text { boosting }\end{array}$ & bar & 300 & 300 & 300 & 75 \\
\hline $\begin{array}{l}\text { Temp. after } \\
\text { the 1st stage } \\
\text { of pressure } \\
\text { boosting }\end{array}$ & ${ }^{\circ} \mathrm{C}$ & 42,4 & 225,6 & 47,8 & 93 \\
\hline $\begin{array}{l}\text { Pressure } \\
\text { after the 2nd } \\
\text { stage of } \\
\text { pressure } \\
\text { boosting }\end{array}$ & bar & - & - & - & 300 \\
\hline $\begin{array}{l}\text { Temp. after } \\
\text { the 2nd } \\
\text { stage of } \\
\text { pressure } \\
\text { boosting }\end{array}$ & ${ }^{\circ} \mathrm{C}$ & - & - & - & 42,4 \\
\hline $\begin{array}{l}\text { Available } \\
\text { heat drop }\end{array}$ & $\mathrm{kJ} / \mathrm{kg}$ & 324,8 & 505,2 & 381,7 & 508,9 \\
\hline Efficiency & $\%$ & 58,16 & 54,15 & 58,07 & 56,39 \\
\hline
\end{tabular}

Table 1. Initial data and calculation results

Calculations of the cycles' indicators in the temperature range $1000-1500{ }^{\circ} \mathrm{C}$ (Fig. 2) are realized. In all cases, the calculation was carried out at an ambient temperature of $20^{\circ} \mathrm{C}$.

The best thermodynamic efficiency in the temperature range up to $1300{ }^{\circ} \mathrm{C}$ is shown by a cycle completely located in the zone of supercritical parameters (Option 1), proposed for consideration by the article authors. Such an arrangement significantly simplifies the technological scheme, since it is possible to use a pump for pressure boosting, but a carbon dioxide condenser is not required (in this option the carbon dioxide density increases due to a decrease in the temperature of supercritical $\mathrm{CO}_{2}$ ). 
However, the available heat drop is significantly reduced by increasing the pressure after the turbine to 75 bar.

With a further initial temperatures' increase, the cycle with a phase transition is most effective (Option 3), proposed by JIHT. At the same time, the presence of a phase transition complicates the technological scheme and also requires an increase in the final pressure to 57.24 bar to ensure the condensation of $\mathrm{CO}_{2}$ at a standard ambient temperature of $20^{\circ} \mathrm{C}$. This reduces the available heat drop, but eliminates the need for a compressor.

The options 2, 4 do not have a phase transition of the cycle fluid and among them the cycle with a two-stage pressure boosting by a compressor and a pump has the best efficiency (Option 4, Allam cycle). This option has the highest available heat drop, but a significantly complicated technological scheme.

The functioning of the cycles under consideration is characterized by a continuous renewal of the cycle fluid due to the additive of $\mathrm{CO}_{2}$ obtained during the combustion of hydrocarbon fuel in oxygen. The water vapor formed during the hydrogen combustion, together with the main $\mathrm{CO}_{2}$ flow, passes through the turbine, and then condenses in the process of heat exchange and then is removed from the cycle (its amount is insignificant and conditioned by the hydrogen of the fuel). The carbon dioxide formed during combustion renews the cycle fluid.

The initial temperature of the cycle fluid will also depend on the amount of combust fuel, since it is heated by mixing with combustion products. An initial temperature increase leads to an increase in the efficiency of the cycles, Fig. 2.

Cycles 1, 3, 4 have an evident maximum efficiency in dependence to temperature, which is associated with the heat recovery operation.

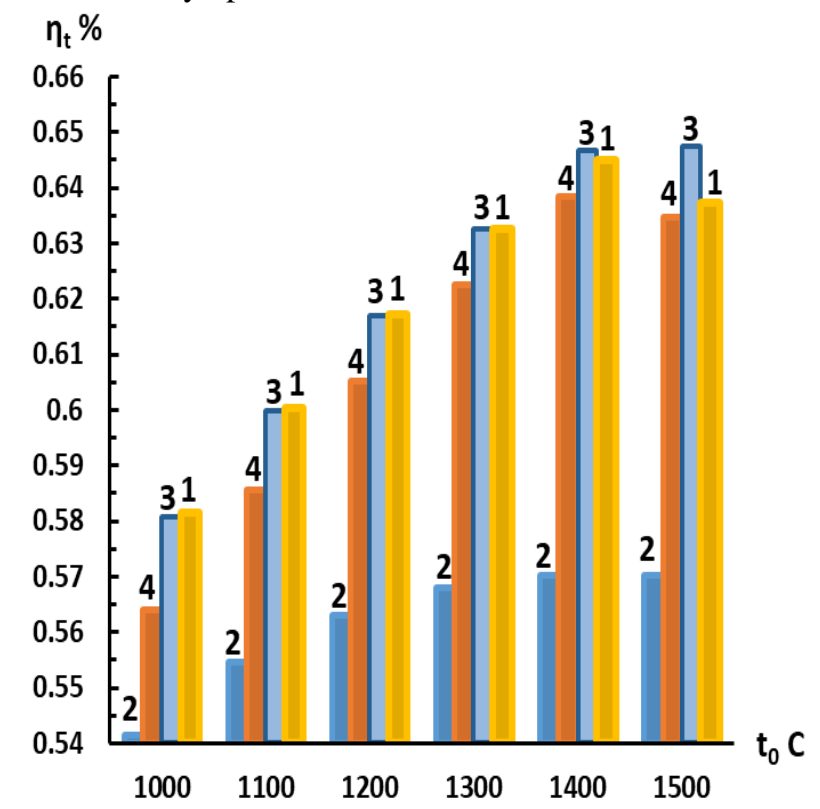

Fig. 2. Dependence of the cycle efficiency on the initial temperature of $\mathrm{CO}_{2}$ : 1-4 - cycle execution options

It can be seen that the cycle located in the supercritical zone has the highest efficiency in the range up to $1300{ }^{\circ} \mathrm{C}$ (Option 1, Fig. 2), the worst efficiency - cycle with a single-stage pressure boosting by the compressor (Option
2, Fig. 2). Moreover, a cycle with supercritical characteristics without a phase transition (Option 1) has almost identical efficiency with the JIHT cycle (Option 3, Fig. 2) practically in the entire temperature range, only slightly yielding to the JIHT cycle at temperatures of $1300-1500{ }^{\circ} \mathrm{C}$.

On the other hand, increasing the initial temperature requires more energy input, that is, burning more fuel. This leads to the fact that more carbon dioxide and water vapor are generated in the combustion chamber. Thus, the proportion of $\mathrm{CO}_{2}(\delta)$ generated in the combustion chamber increases, which will then need to be removed from the cycle and utilized to achieve zero emissions.

It was determined that in the considered variants the continuous removal of carbon dioxide from the cycle will be $2.7-5 \%$, depending on its configuration.

Figure 3 shows a graph of the dependence of the available heat drop on the initial temperature of the working fluid for cycles of various architectures. Since the calculation is made for $1 \mathrm{~kg}$ of $\mathrm{CO}_{2}$ passing through the turbine, this graph actually reflects the specific power rating.

Lines 2 and 4 are superimposed, since variants of cycles 2 and 4 have the same initial and final parameters of the cycle fluid. The insignificant difference in the available heat drop between these two options is due to the different amount of water vapor per $\mathrm{kg}$ of carbon dioxide in different cycle configurations. The difference in water content is explained by the different amount of fuel burned to provide the initial parameters due to the different efficiency of the cycles.

\section{$\mathrm{H}_{0}, \mathrm{~kW} / \mathrm{kg} \mathrm{CO}$}

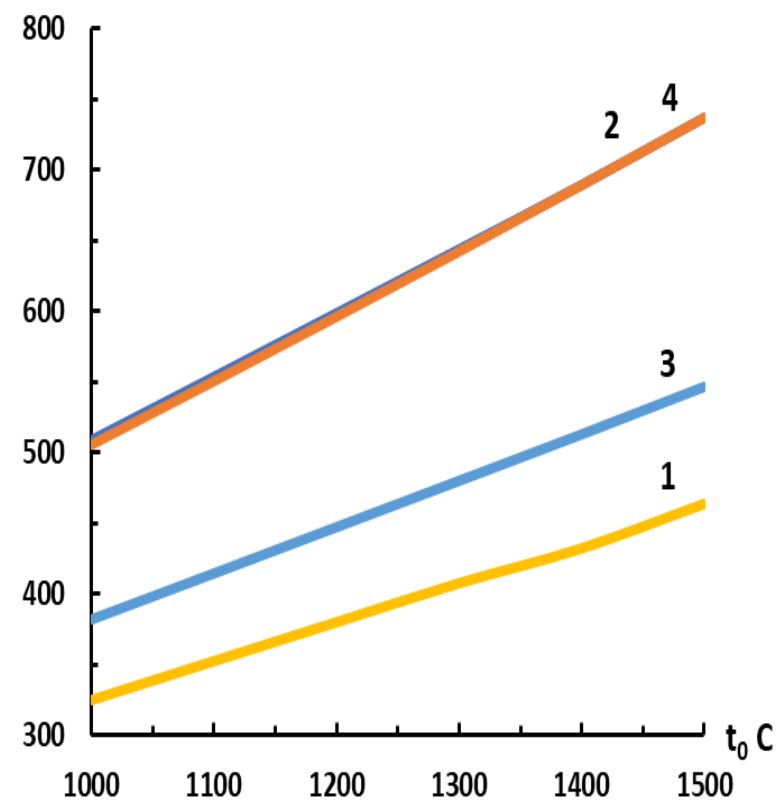

Fig. 3. Dependence of the available heat drop on the initial temperature of $\mathrm{CO}_{2}: 1-4$ - cycle execution options

Cycle 3 (JIHT) has a lower heat drop due to the increased final pressure to ensure the condensation process at ambient temperature. Cycle 1 also loses out in terms of heat drop due to the increased final pressure, 
since it is completely located in the zone of supercritical parameters.

A feature of cycles on carbon dioxide is the requirement of high initial parameters (pressure up to 300 bar and temperature at the level of $1000-1500{ }^{\circ} \mathrm{C}$ ) of the working fluid in order to achieve efficiency indicators at the level of $55-65 \%$. The high parameters of carbon dioxide cycles, as well as the unconventional chemical composition of the cycle fluid, necessitate the development of the foundations for the design of power equipment, among which a supercritical carbon dioxide turbine deserves special attention.

Cycle fluid temperature in $\mathrm{CO}_{2}$-cycles are comparable to temperatures in modern gas turbine cycles, but much higher than temperatures in steam turbine cycles. At the same time, the maximum pressure does not exceed the pressure in the latest steam turbines, but is several times higher than the pressure in gas turbines.

To date, there are few materials in the publicly available literature on the methodology for the development of this kind of turbines. Separate recommendations for the design of the rotor, including the choice of materials for its manufacture and a possible method for cooling the blades, were proposed by the developers of the Allam cycle in [9]. The turbine design for a $50 \mathrm{MW}$ demonstration unit is described in [6]. An attempt to systematize design approaches and determine recommendations for designing a flow path is presented in [13]. It is also noted there that the level of initial temperatures for existing gas turbines approached to 1700 ${ }^{\circ} \mathrm{C}$ [14]. However, the initial pressure of the cycle fluid in front of the gas turbine usually does not exceed 4-4.5 $\mathrm{MPa}$. A high initial pressure is inherent in the steam turbine cycle. Recently, much attention has been paid to the development of power plants for supercritical and ultrasupercritical initial parameters [15].

An important confirmation of the possibility of creating a turbine for carbon dioxide with high initial parameters is the example of the Japanese company Toshiba ESS, which developed and manufactured a turbine with an electric power of $25 \mathrm{MW}$ (50 MW thermal) with initial parameters of $300 \mathrm{bar}, 1150{ }^{\circ} \mathrm{C}$ [16]. The turbine and high pressure combustion chamber, which are key components of the carbon dioxide cycle, were supplied in 2016 and 2017 respectively for the Allam NET Power pilot plant located in La Porte, Texas, USA $[17,18]$.

\section{Conclusion}

Variants of thermodynamic $\mathrm{CO}_{2}$-cycles with zero emissions, features of their modeling and research methodology are presented.

It is calculated that the efficiency of the considered cycles with an initial temperature of $1000{ }^{\circ} \mathrm{C}$ is $0,54-0,58$ depending on their architecture. Thermodynamic efficiency can be increased to 0,65 with an increase in the initial temperature of the cycle fluid to $1500{ }^{\circ} \mathrm{C}$. It was also determined that the continuous removal of carbon dioxide from the cycle will be $2.7-5 \%$, depending on its configuration.
The high thermal efficiency of $\mathrm{CO}_{2}$ cycles allows to assume that the final efficiency of the power plant will also be high. This, in turn, allows to have high costs for own needs, while the final efficiency will be comparable to traditional coal-fired power plants, but when zero emissions are achieved.

Issues related to the provision of oxygen combustion, preparation of fuel for combustion, the operation of heat regenerators, machines and apparatuses with which the power plant should be completed, as well as the disposal of $\mathrm{CO}_{2}$ removed from the cycle require further study.

\section{References}

1. S.P. Filippov, 15th International Scientific and Technical Conference «Problems of energy systems and thermal power complexes», (2020)

2. European Commission: EU Green Deal (carbon border adjustment mechanism). URL: https://ec.europa.eu/info/law/better-regulation/haveyour-say/initiatives/12228-Carbon-BorderAdjustment-Mechanism

3. Department for Multilateral Economic Cooperation and Special Projects of Ministry of Economic Developmentof the Russian Federation. International Approaches to Carbon Pricing, 2021 (In Russ) - URL: https://www.economy.gov.ru/material/file/c13068c69 5b51eb60ba8cb2006dd81c1/13777562.pdf

4. S.V. Alekseenko, XXXVI Siberian Thermophysical Seminar, (2020)

5. G.G. Olkhovskii, Thermal Engineering, 63(10), 679689 (2016)

6. R. Allam, S. Martin and others, Energy Procedia, 114, 5948-5966 (2017)

7. A.S. Kosoi, Yu.A. Zeigarnik, O.S. Popel', M.V.Sinkevich, V.Ya. Shterenberg, Thermal Engineering, 65(9), 597-605 (2018)

8. Wolfgang Sanz Graz Cycle. - A Zero Emission Power Plant for CCS (Carbon Capture and Storage) http://www.graz-cycle.tugraz.at/

9. R.J. Allam et al, Energy Procedia, 37, 1135-1149 (2013)

10. S. Budinis, S.Krevor, Niall Mac Dowell, N. Brandon, A. Hawkes, Energy Strategy Reviews, 22, 61-81 (2018)

11. D.Y.C. Leung, G. Caramanna, M.M. Maroto-Valer, Renew. Sustain. Energy Rev., 39, 426-443 (2014)

12. Francesco Dalla Longa, Remko Detz, Bob van der Zwaan, International Journal of Greenhouse Gas Control, 103, 103133 (2020)

13. N. Rogalev, V. Kindra and others, Vestnik IGEU, 3, 5-14, (2018) In Russ

14. T. Torigoe, Y. Okajima, I. Okada, J. Masada, K. Tsukagoshi, Materials Science Forum, 879, 19801986, (2017)

15. N. Rogalev, V. Prokhorov, A. Rogalev, I. Komarov, V. Kindra, International Journal of Applied Engineering Research, 11(18), 9297-9306, (2016)

16. Toshiba Global. News Release (1 Nov, 2016). URL: https://www.global.toshiba/ww/news/corporate/2016/ 11/pr0101.html 
17. New Energy Technology company, NET Power.

URL: https://netpower.com/

18. Toshiba Energy Systems \& Solutions Corporation /

Press Releases \& News. - 2018. - URL:

https://www.toshiba-

energy.com/en/info/info2018 0615.htm 